\title{
Anisotropic Characteristic of Insect (Lepidoptera) wing Surfaces
}

\author{
Gang Sun \\ School of Life Science \\ Changchun Normal University \\ Changchun, Jilin Province, P. R. China \\ E-mail: sungang@nenu.edu.cn
}

\author{
Yan Fang* \\ School of Life Science \\ Changchun Normal University \\ Changchun, Jilin Province, P. R. China \\ E-mail: fangyan124@aliyun.com \\ * Corresponding Author
}

\begin{abstract}
The anisotropism, superhydrophobicity, adhesion, and chemical composition of the insect (Lepidoptera) wing surfaces are investigated by a scanning electron microscope (SEM), a contact angle (CA) meter and a Fourier transform infrared spectrometer (FTIR). The wetting mechanism of the wing is discussed from the perspective of biological coupling. The wings display multiple-dimensional morphological anisotropism. The micrometric scales constitute the primary structure. The submicrometric vertical ribs and horizontal bridges on the scales constitute the secondary structure. The nano stripes on the vertical ribs and horizontal bridges constitute the tertiary structure. The wing surfaces are of superhydrophobicity $\left(\mathrm{CA} 152.5 \sim 158.6^{\circ}\right)$ and low adhesion (sliding angle $1 \sim 4^{\circ}$ ). In addition, the water droplet exhibits anisotropic sliding behavior on the wing surfaces. The scale plays a crucial role in determining the self-cleaning property of the wing. The coupling effect of material element and structure element contributes to the complex wettability of the wing surface. The insect wings can be potentially used as a template for biomimetic design of functional surface with special wettability. This work may offer insights into the preparation of smart interfacial material and directional self-cleaning coatings.
\end{abstract}

Keywords-Superhydrophobicity; Adhesion;

Selfcleaning; Anisotropism; Insect wing.

\section{INTRODUCTION}

Anisotropism is one of the most important properties of a patterned solid surface. The anisotropic rough surface results in special wetting and dewetting characteristics in different directions. One example is the anisotropic dewetting phenomenon on the superhydrophobic rice leaf surface. The sliding angle (SA) of a water droplet is greatly influenced by the anisotropic arrangement of the papillae on the rice leaf[1]. The anisotropic wettability has drawn much attention and has been applied for fabrication of selfassembling patterned surfaces[2], submicrometric channel lattices with alternating wettability [3] and ricelike aligned carbon nanotubes (ACNT) film[4]. The anisotropic dewetting property may bring interesting insights into design of lossless liquid transportation channels and novel microfluidic valves, in which liquids can be driven in a preferred direction. Bio-surface is an ideal bio-template for artificial fabrication due to some excellent properties, such as attractive iridescence, superhydrophobic characteristics and quick heat dissipation ability[5-11]. In the present paper, the anisotropism of the rough surface on the insect (Lepidoptera) wings are investigated and discussed the wetting mechanism from the perspective of biological coupling. This work cannot only promote the understanding of anisotropic wetting phenomenon on bio-surfaces, but provide inspiration for design and preparation of smart fluid-controllable interface and directional self-cleaning material.

\section{MATERIALS AND METHODS}

\section{A. Materials}

The insect specimens of ten species (five butterfly species, five moth species) were collected in Changchun City, Jilin Province, China from June to October 2014. The wings were cleaned, desiccated and flattened, then cut into pieces with the size of $5 \mathrm{~mm} \times 5 \mathrm{~mm}$ from the discal cell (Fig. 1). The distilled water for the measurements of CA and SA was purchased from Tianjin Pharmaceuticals Group Co. Ltd., China. The volume of water droplet was $5 \mu \mathrm{l}$.

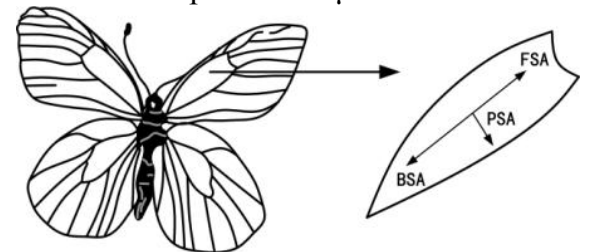

Figure 1. The experimental area and the SAs of water droplet in different directions (FSA: forward SA; BSA: backward SA; PSA: perpendicular SA).

\section{B. Methods}

After gold coating by an ion sputter coater (Hitachi E-1045, Japan), the wing pieces were observed and photographed by a SEM (Hitachi SU8010, Japan). A video-based CA measuring system(DataPhysics OCA20, Germany) was used to measure the $\mathrm{CA}$ of a water droplet on the wing surfaces by sessile drop method at room temperature of $25 \pm 1{ }^{\circ} \mathrm{C}$. The SA was measured in three directions, including forward SA (FSA, the SA of droplet from the wing basal to the wing terminal), backward SA (BSA, the SA of droplet from the wing terminal to the wing basal), and perpendicular SA (PSA, the SA of droplet perpendicular to the major axis of the wing) (Fig. 1). The chemical composition of the wing 
surfaces were investigated by means of FT-IR (Nicolet FT-IR200, USA).

\section{RESULTS AND DISCUSSION}

A. Anisotropism of the micro-morphology on the wing surfaces

The wing surfaces exhibit multiple-dimensional rough structures. The micrometric scales constitute the primary structure. The shapes of the scales of butterfly and moth are similar [Fig. 2(a), 2(b)]. For butterfly, the length of the scale is $98 \sim 257 \mu \mathrm{m}$, the width is $38 \sim 86 \mu \mathrm{m}$, the spacing is $42 \sim 75 \mu \mathrm{m}$. For moth, the length of the scale is $106 \sim 342 \mu \mathrm{m}$, the width is $57 \sim 123 \mu \mathrm{m}$, the spacing is $62 \sim 146 \mu \mathrm{m}$. The submicrometric vertical ribs and horizontal bridges on the scales constitute the secondary structure. The vertical ribs and horizontal bridges are linked as grids, some vertical ribs have branches [Fig. 2(c), 2(d)]. For butterfly, the height of the vertical rib is $276 \sim 687 \mathrm{~nm}$, the breadth is $195 \sim 428 \mathrm{~nm}$, the spacing is 932 1405 $\mathrm{nm}$. For moth, the height of the vertical rib is $312 \sim 735 \mathrm{~nm}$, the breadth is $262 \sim 534 \mathrm{~nm}$, the spacing is $981 \sim 1633 \mathrm{~nm}$. The nano stripes distributing regularly on the vertical ribs and horizontal bridges constitute the tertiary structure [Fig. 2(e), 2(f)]. The primary, secondary and tertiary structures all display remarkable anisotropism.

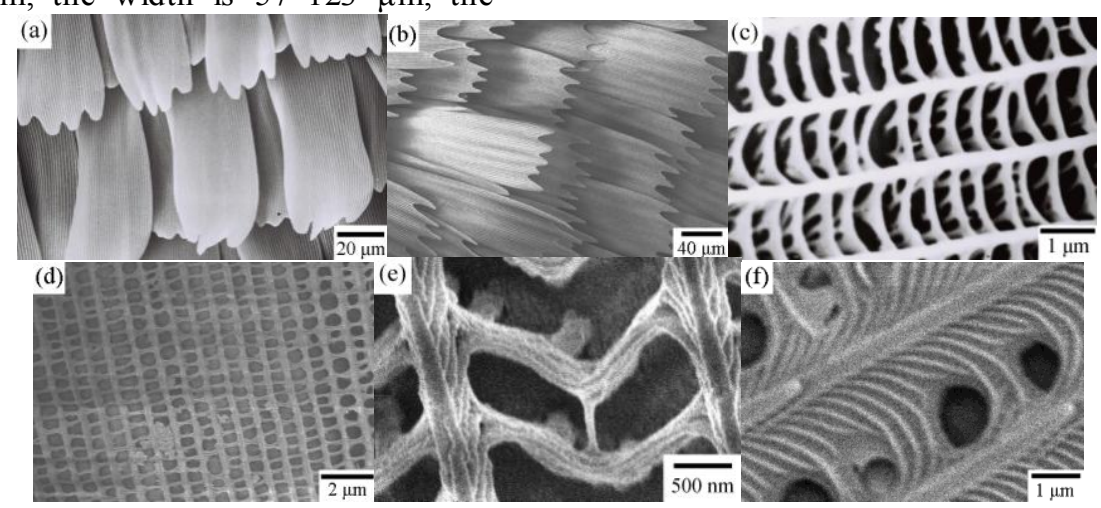

Figure 2. The multiple-dimensional micro/nano microstructures of the insect wing surfaces.

(a), (b) Primary structure (micrometric scales) of butterfly and moth, respectively; (c), (d) Secondary structure (submicrome tric vertical ribs and horizontal bridges) of butterfly and moth, respectively; (e), (f) Tertiary structure (nano stripes) of butterfly and moth, respectively.

B. Anisotropism of the self-cleaning property on the wing surfaces

The wing surfaces exhibit low adhesion. For butterfly, the range of FSA is $1 \sim 4^{\circ}$, BSA $6 \sim 11^{\circ}$, PSA $5 \sim 8^{\circ}$. For moth, the range of FSA is $1 \sim 3^{\circ}$, BSA $6 \sim 9^{\circ}$, PSA $4 \sim 7^{\circ}$ (Table 1 ). Meanwhile, the wing surfaces are superhydrophobic $\left(\mathrm{CA}>150^{\circ}\right)$. The range of $\mathrm{CA}$ is $152.5 \sim 158.6^{\circ}$. The large $\mathrm{CA}$ and small SA imply outstanding self-cleaning characteristic of the wing surfaces. There are extremely significant differences between FSA and BSA $(\mathrm{P}<0.01)$, between FSA and PSA $(\mathrm{P}<0.01)$, as well as between BSA and PSA $(\mathrm{P}<0.01)$. The self-cleaning performance displays remarkable anisotropism on the wing surfaces. The wing surfaces are of low adhesive superhydrophobicity.

TABLE I. CA AND SA OF WATER DROPLET ON THE INSECT WING SURFACES

\begin{tabular}{|c|c|c|c|c|c|c|c|}
\hline \multirow{3}{*}{ Group } & \multirow{3}{*}{ Species } & \multicolumn{2}{|c|}{$\mathrm{CA}\left({ }^{\circ}\right)$} & \multicolumn{4}{|c|}{$\mathrm{SA}\left({ }^{\circ}\right)$} \\
\hline & & \multirow{2}{*}{$\begin{array}{c}\text { With } \\
\text { scale }\end{array}$} & \multirow{2}{*}{$\begin{array}{c}\text { Without } \\
\text { scale }\end{array}$} & \multicolumn{3}{|c|}{ With scale } & \multirow{2}{*}{$\begin{array}{l}\text { Without scale } \\
\text { FSA/BSA/PSA }\end{array}$} \\
\hline & & & & FSA & BSA & PSA & \\
\hline \multirow{6}{*}{ Butterfly } & Clossiana thore & 155.4 & 105.3 & 2 & 11 & 8 & $>65$ \\
\hline & Everes argiades & 156.3 & 110.2 & 4 & 7 & 6 & $>65$ \\
\hline & Libythea celtis & 152.7 & 102.7 & 1 & 9 & 5 & $>65$ \\
\hline & Pyrgus malvae & 154.8 & 99.6 & 3 & 7 & 6 & $>65$ \\
\hline & Vanessa indica & 152.5 & 116.5 & 1 & 6 & 7 & $>65$ \\
\hline & Average & 154.3 & 106.9 & 2 & 8 & 6 & $>65$ \\
\hline \multirow{6}{*}{ Moth } & Amphipyra erebina & 157.6 & 105.6 & 3 & 8 & 4 & $>65$ \\
\hline & Chlorodontopera mandarinata & 152.5 & 112.4 & 1 & 9 & 5 & $>65$ \\
\hline & Mamestra brassicae & 156.2 & 104.5 & 2 & 7 & 6 & $>65$ \\
\hline & Parum colligate & 155.7 & 106.7 & 3 & 7 & 4 & $>65$ \\
\hline & Scopula pudicaria & 158.6 & 111.3 & 2 & 6 & 7 & $>65$ \\
\hline & Average & 156.1 & 108.1 & 2 & 7 & 5 & $>65$ \\
\hline
\end{tabular}

\section{Mechanism of the anisotropic wettability on the} wing surfaces

The wing surfaces of butterfly and moth display highly similar absorption characteris tic of FT-IR spectra. The absorption peaks are at 3287, 2935, 2875, 1646, $1531,1378,1223,1141,1065 \mathrm{~cm}-1$ for butterfly, 3296, $2945,2883,1657,1542,1385,1232,1152,1074 \mathrm{~cm}-1$ for moth (Fig. 3). These absorption bands result from stretching vibration, skeletal vibration, deformation vibration or in-plane bending vibration of the bases (e.g. $-\mathrm{CH} 3,-\mathrm{CH} 2,-\mathrm{C}-\mathrm{CH} 3, \mathrm{C}-\mathrm{H}, \mathrm{O}-\mathrm{H}, \mathrm{C}=\mathrm{O}, \mathrm{C}-\mathrm{O}, \mathrm{N}-\mathrm{H})$ in chitin, protein or fat. The wing surfaces are composed mainly of naturally hydrophobic material with an intrinsic CA of $95^{\circ}[8]$. However, much higher hydrophobicity cannot result from the chemical composition alone. Due to the hierarchical rough 
structures on the wing surface, the water droplet stands on the tips of the vertical ribs. Much air is left under the droplet. The actual contact area between the water droplet and the wing surface is so small that the droplet forms an almost perfect sphere. The solid-liquid-gas triple contact lines (TCL) are expected to be contorted and unstable. The multiple-dimensional microstructure plays a crucial role in the complex wettability of the wing surfaces. In a contrast test, the scales are removed from the wing surfaces. The $\mathrm{CA}$ decreases by 23.6\% 35.7\% for butterfly, 26.3 33. $1^{\circ}$ for moth (Table 1). All the SAs (FSA, BSA, PSA) increase above $65^{\circ}$ (the maximum inclination angle of the sample table is $65^{\circ}$ ). The low adhesive superhydrophobicity of the wing surfaces ascribes to the coupling effect of material element and structural element.

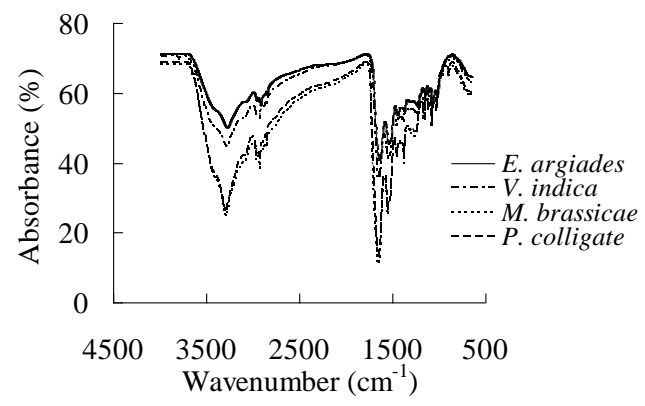

Figure 3. FT-IR spectra of butterfly and moth wing surface.

\section{Biological significance of the anisotropic property on the wing surfaces}

The anisotropism of SA and self-cleaning property on the wing surfaces is the result of the oriented micromorphology and the energy barrier difference in various directions. Compared with the sliding of droplet from the wing terminal to the wing basal (BSA), when the droplet slides from the wing basal to the wing terminal (FSA), the anisotropic microstructures exert less influence in hampering droplet sliding, the droplet is highly instable and can roll off more easily, so SA decreases. This marvelous property results from longterm co-evolution of the flying insect and the environment, and endows the wings with the ability of directional easy-cleaning in a watery environment. Such a self-cleaning function is of essential biological significance for the flying insect. Even a very slight tilting $\left(1 \sim 4^{\circ}\right)$ of the wing is sufficient to cause the water droplet to roll off and take away the contaminating particles effectively. The flying insect can lighten body burden readily, increase flight stability and efficiency, optimize energy budget. Thus, the insect can get more opportunities to survive and thrive.

\section{CONCLUSIONS}

The insect (Lepidoptera) wing surfaces are of low adhesion (SA $1 \sim 4^{\circ}$ ) and superhydrophobicity (CA $\left.152.5 \sim 158.6^{\circ}\right)$. The wing surfaces are composed of naturally hydrophobic material (chitin, protein, fat, etc.), and possesses hierarchical rough structures. The cooperative effect of material element and structure element leads to the complex wettability of the wing surfaces. The wing surfaces exhibit anisotropism of micro-morphology and self-cleaning property, which is of critical biological significance for the survival of insect. The wing surfaces are ideal bio-templates for development of novel functional materials. This work does not only promote the understanding of wetting mechanism of bio-surfaces, but also brings insights into biomimetic preparation of novel self-cleaning coatings and anis otropic wetting substrate.

\section{ACKNOWLEDGMENTS}

This work was financially supported by the National Natural Science Foundation of China (50875108), the Natural Science Foundation of Jilin Province, China (201115162), Science and Technology Project of Educational Department of Jilin Province, China (2009210, 2010373, 2011186).

\section{REFERENCES}

[1] T.L. Sun, L. Feng, X.F. Gao et al., Bioinspired surfaces with special wettability, Accounts Chem. Res.38,644 (2005).

[2] A.M. Higgins, R.A.L. Jones, Anisotropic spinodal dewetting as a route to self-assembly of patterned surfaces, Nature 404,476 (2000).

[3] M. Gleiche, L.F. Chi, H. Fuchs, Nanoscopic channel lattices with controlled anisotropic wetting, Nature403,173 (2000).

[4] H. Liu, J. Zhai, L. Jiang, Wetting and anti-wetting on aligned carbon nanotube films, Soft Matter2,811 (2006).

[5] S. Yang, J. Ju, Y.C. Qiu et al., Superhydrophobic materials: peanut leaf inspired multifunctional surfaces, Small10,214 (2014).

[6] B. Bhushan, E.K. Her, Fabrication of superhydrophobic surfaces with high and low adhesion inspired from rose petal, Langmuir26,8207 (2010).

[7] Y. Fang, G. Sun, T.Q. Wang et al., Hydrophobicity mechanism of non-smooth pattern on surface of butterfly wing, Chin. Sci. Bull.52,711 (2007).

[8] X.J. Wang, Q. Cong, J.J. Zhang et al., Multivariate coupling mechanism of NOCTUIDAE moth wings' surface superhydrophobicity, Chin. Sci. Bull.54,569 (2009).

[9] G. Sun, Y. Fang, Q. Cong et al., Anisotropism of the nonsmooth surface on butterfly wing, J. Bionic Eng.6,71 (2009).

[10] Y. Fang, G. Sun, Q. Cong, Effects of methanol on wettability of the non-smooth surface on butterfly wing, J. Bionic Eng.5,127 (2008).

[11] Y. Fang, G. Sun, Y.H. Bi et al., Multiple-dimensional micro/nano structural models for hydrophobicity of butterfly wing surfaces and coupling mechanism, Science Bulletin60,256 (2015). 